\title{
A POESIA INFANTIL DE JOÃO KÖPKE POR CAMINHOS TEÓRICOS E METODOLÓGICOS ${ }^{1}$
}

\author{
Morgana de Medeiros Farias (UFPB) \\ Daniela Maria Segabinazi (UFPB)
}

Resumo: O manuscrito Versos para os pequeninos, escrito no século XIX, possivelmente entre os anos 1886 e 1897, pelo educador João Köpke, contém 24 poemas para crianças, estes que se aproximam do que conhecemos como poesia concreta. Essa obra esteve por muito tempo sob a tutela da família Köpke, sem ser conhecida e muito menos analisada pela comunidade acadêmica. Até então, tínhamos a ideia de que o autor destinava sua produção apenas a livros de leitura, estes que serviam para oferecer ensinamentos às crianças, fossem eles inseridos no âmbito escolar ou voltados aos valores éticos e morais que o período republicano solicitava. Foi através da Profa. Norma Ferreira, da Faculdade de Educação da Unicamp, que pudemos ter contato, apenas em 2017, com a obra citada, em edição fac-símile, esta que lhe serviu de objeto de estudo em sua tese de pós-doutorado. Deste modo, constatamos que o manuscrito foi bem produzido se considerarmos suas variadas esferas estéticas, desde o ritmo até as unidades semânticas, motivo pelo qual nos dispusemos a analisá-lo, objetivando conferir-lhe mais visibilidade, já que o mesmo ainda se encontra no anonimato. Para isso, lançamos mão de embasamentos teóricos, utilizando-nos de bibliografias como Alves (2016), Camargo (2017), Bosi (1988), dentre outros, bem como optamos pelo poema intitulado "Meu cavallo" para que pudéssemos propor uma metodologia eficaz de trabalho com o mesmo em sala de aula. Assim, aos poucos, acreditamos que é possível dar a João Köpke o reconhecimento devido.

Palavras-chave: João Köpke; Século XIX; Literatura infantil; Poesia.

Resumen: El manuscrito Versos para los pequeños, escrito en el siglo XIX, posiblemente entre 1886 y 1897, por el educador João Köpke, contiene 24 poemas para niños, que se acercan a lo que conocemos como poesía concreta. Este trabajo ha estado durante mucho tiempo bajo la tutela de la familia Köpke, sin el conocimiento y mucho menos analizado por la comunidad académica. Hasta entonces, teníamos la idea de que el

1 Título em espanhol: "Poesía infantil de john köpke por caminos teóricos y metodológicos". 
autor tenía la intención de su producción solo para leer libros, que servían para ofrecer enseñanzas a los niños, ya sea que se insertaran en la escuela o se centraran en los valores éticos y morales que el período republicano solicitaba. Fue a través de Profa. Norma Ferreira, de la Facultad de Educación de la Unicamp, pudimos tener contacto, solo en 2017, con el trabajo mencionado, en edición facsímil, que sirvió como objeto de estudio en su tesis postdoctoral. Por lo tanto, descubrimos que el manuscrito estaba bien producido si consideramos sus diversas esferas estéticas, desde el ritmo hasta las unidades semánticas, por lo que estábamos dispuestos a analizarlo, con el objetivo de darle más visibilidad, ya que todavía está en el anonimato Para esto, utilizamos fundamentos teóricos, utilizando bibliografías como Alves (2016), Camargo (2017), Bosi (1988), entre otras, además de optar por el poema titulado "Mi Cavallo" para poder proponer una metodología efectiva. trabajando con él en el aula. Poco a poco creemos que es posible darle a John Köpke el debido reconocimiento.

Palabras Ilave: João Köpke; Siglo XIX; Literatura infantil; Poesía

\section{CONSIDERAÇÕES INICIAIS}

A produção literária infantil, assim como a adulta, está diretamente ligada às relações que o leitor estabelece com o meio em que vive. Nenhum escrito é neutro, tem finalidades que vão desde o contexto de produção, passando pela recepção, circulação, até chegar à utilização. Para Oliveira (2017), "Este material destinado às crianças surge no Brasil intrinsicamente ligado ao ambiente educacional, desenvolvendo-se, em primeira estância, como recurso didático para a disseminação de valores vinculados à Primeira República brasileira" (p.12).

Considerando a necessidade de buscar os percussores da literatura infantil e juvenil do nosso país, pudemos 
ter conhecimento acerca de escritores responsáveis por produções de considerável valor, pouco (ou nada) citados, como é o caso de João Köpke. O referido autor se formou em Direito, nasceu em Petrópolis, no Rio de Janeiro, em 1852 e por ser escritor e educador, o nome dele é mais lembrado por pesquisadores da área de educação, embora anteceda Monteiro Lobato com a literatura de sua autoria.

As contribuições de Köpke para a literatura infantil agora estão mais em evidência através de sua obra manuscrita, Versos para os pequeninos, criada entre 1886 e 1897, guardada pela família do educador por mais de um século e difundida pela Faculdade de Educação da UNICAMP. O livro em questão é montado com 24 poemas e 24 estampas como o autor mesmo chamava - e se aproxima do que hoje nós conhecemos como poesia concreta, de caráter visual, que procura estruturar o texto escrito a partir do espaço disponível.

No prefácio da obra Versos para os pequeninos, Norma Ferreira, pesquisadora responsável por trazer à tona o referido manuscrito, fala um pouco sobre as características da obra do autor, atentando para o fato de ela ter sido escrita há pelo menos 122 anos e apresentar uma linguagem que extrapola o nível discursivo e a estrutura formal, fazendo da 
escrita um exercício gráfico, estético e lúdico. Fala, ainda, que Köpke é interpretado como um escritor que visava produzir para crianças sob um viés republicano que predominava na segunda metade do século XIX.

Diferentemente dos autores da época, João Köpke não vinculou, à maioria dos versos desse manuscrito, temas como a moral, para ensinar às crianças bons comportamentos, como serem educadas, religiosas ou caridosas, ele brinca com o conteúdo, este que têm uma disposição lúdica invertida visualmente, que parece descrever o que há de mais substancial nas estampas que estão ao lado da escrita. Assim, intencionamos analisar o poema "Meu cavallo", presente na obra citada acima, considerando texto, temática, disposição, poeticidade, provocação estética, dentre outras manifestações literárias.

Optamos por essa análise objetivando tirar do anonimato a obra em questão, conferindo-Ihe o caráter de publicação inédita, escrita de próprio punho por João Köpke, ratificando sua singularidade como autor de literatura infantil, bem como intelectual da educação. Além dos pontos citados, vale adentrar, igualmente, ao temário trabalhado pelo autor, este que se mostra peculiar e inventivo se considerarmos que há muita pedagogização ligada à literatura infantil em geral. 
Muitos temas são voltados aos animais, bichinhos que encantam as crianças, como é o caso do poema "A garatarrada", que descreve alguns gatinhos e os seus costumes. Através dessa obra, a máxima de que se pode aprender brincando, embora ensinar, propriamente, não seja a primeira intenção da mesma, é uma realidade. As barreiras entre o real e o imaginário não são intransponíveis. Diante disso, nos deteremos à análise do poema escolhido nos utilizando de teorias voltadas à literatura infantil, bem como ao gênero poético, apresentando, no decorrer deste artigo, uma proposta metodológica que abarque o trabalho com o poema em questão.

\section{JOÃO KÖPKE: POESIA INFANTIL E (RE)CONHECIMENTO}

Através de pesquisas realizadas a respeito da obra de João Köpke, sobretudo acerca dos Versos para os pequeninos, percebemos que as teorias e a difusão da obra desse autor ainda são escassas, sobretudo por se tratar de poesia infantil, que é um gênero literário que perde espaço para as narrativas, devido ao público que nem sempre reconhece o seu valor. Vemos, assim, que empreender um estudo acerca do autor e da obra em questão é importante para a literatura como um todo, de forma que poderemos dar visibilidade a produções que estão há muito tempo dispersas entre tantas outras obras. 
Köpke, assim como Lobato, - reservadas as suas peculiaridades, obviamente -, se importava em atribuir mais liberdade e informalidade à infância, algo que não se encaixava nas propostas pedagógicas que predominavam no início do século $X X$, que apreciavam mais poemas e narrativas edificantes e crianças bem educadas e comportadas. Somente quatro em um universo de vinte e quatro poemas desse manuscrito apresentam, de certa forma, um conteúdo que pode ser visto como moralizante, sendo eles: "Dona Boneca" (p.25); “Os Bonecos" (p.13); “Philosofia" (p.39) e "Os cordeirinhos (p.17)".

Parece que Versos para os pequeninos rompe, de certa forma, com essa perspectiva registrada pela história da literatura e dos livros escolares para crianças. Ele traz adaptações de conhecidas cantigas infantis populares que podem embalar, como parlendas, como é o caso, do poema "O balanço" (p.5). Traz brincadeiras próprias do universo infantil, com trocadilhos e musicalidade, como por exemplo, "Andar de cavalinho" em "Meu cavallo" (p.43). Traz crianças que se recusam a obedecer ordens e, como em "A Lua", decidem não brincar mais e mandam-na [...] "às batatas". (p.7). (FERREIRA, 2016, p.61)

Mesmo a poesia adulta perde espaço para as narrativas. No caso da poesia infantil a questão se torna ainda mais 
problemática. Muitas vezes a própria escola promove a ruptura entre a criança e a poesia, pelo modo como empreende o estudo, a leitura e a prática de trabalho com o texto poético. Ainda segundo Gonçalves (2008), a poesia, com sua linguagem emotiva, toca os pequenos sensivelmente, pois têm uma forma particular e diferente do adulto de ver o mundo.

Segundo Camargo (2001, p.88), a poesia infantil brasileira surgiu através da escola, visando principalmente a aprendizagem da língua portuguesa. Além disso, as composições em verso foram utilizadas como recurso didático para convalidar os valores ideológicos republicanos, seguindo um modelo moral e cívico. Isso João Köpke não fez em Versos para os pequeninos, apesar de ter vivido esse momento histórico para o Brasil, o que é muito interessante, já que ele não seguiu "o fluxo", mas compôs da forma como achava mais adequada.

Köpke não está preocupado em "formar" a criança, apenas de acordo com o modelo de bom comportamento da época. Em um dos poemas, por exemplo, as crianças mandam a lua "plantar batatas", em outro, a filosofia é representada por uma gata que está mais preocupada com a comida do que com as ideias, ou seja, em Versos para os pequeninos, os gatos fazem travessuras, jogam tinteiro e cadernos no chão, as crianças bagunçam 
a casa e questionam os adultos, e a escola que ensina "ba, be, bi, bo, bu" aparece como "uma amolação". (FERREIRA, 2017b)

Como educador, Köpke se preocupou em buscar meios de instituir mudanças plausíveis no ideário educacional, rechaçando aquilo que o mercado editorial oferecia à escola e esta, por conseguinte, distribuía às crianças. Corroborando com Ferreira (2016b), o projeto de Köpke para a educação da literatura é baseado na oralidade, enquanto a escola baseia-se predominantemente na escrita. A escola adota livros didáticos individuais, leitura silenciosa, discussões ultrapassadas acerca da poesia, algo que acaba por distanciar os alunos desse gênero literário, já que, com isso, parte dos educadores visa mais a atribuição de notas do que a própria compreensão.

Gênero particularmente difícil, os maiores equívocos de realização da poesia para crianças ocorrem quando se diminui ou se desconhece o leitor infantil. No primeiro caso, incide-se na poesia infantilizada, que subestima o leitor com versos que não permitem nenhuma aventura estimulante da palavra. No outro extremo, está a poesia que não consegue prever o universo da criança e comete impropriedades de vocabulário, conceitos e sentimentos. Faz escolhas incompreensíveis com vivências limitadas daquele que pretende atingir. É o caso das

2 Entrevista concedida pela pesquisadora Norma Sandra de Almeida Ferreira ao Jornal da Unicamp, em maio de 2017. 
composições poéticas sobre percepções e disposições emocionais próprias do adulto, mas irreconhecíveis, ou sem apelo nenhum para uma criança, como por exemplo, a nostalgia. (CADEMARTORI, 2009, p.71)

Em Versos para os pequeninos, como já mencionamos, há imagens, anteriormente chamadas de estampas, para cada poema, algo que permite um trabalho rico com o gênero, pois elas antecipam a leitura daquilo que está escrito. Os poemas vêm marcados com números no início de seus versos ou estrofes, indicando que se podem alternar as vozes, o que inspira uma leitura oralizada e coletiva. Köpke focaliza um tipo de literatura que preza pelo lúdico, a sonoridade, a semântica, além de se utilizar de figuras e desenhos que tornam o texto mais rico visualmente.

O leitor de poesia que procura acompanhar parte dessa produção muitas vezes se depara com questões sérias, que a crítica literária voltada para a literatura infantil precisa enfrentar. Uma delas é o apelo mercadológico que leva um escritor a publicar dezenas de livros repetindo temas, procedimentos, transformando o que foi um achado de poetas como Cecília e Sidónio Muralha em variação sobre o mesmo tema, sem quase nunca alcançar o nível estético de poemas anteriores. (ALVES, 2010, p.261)

As poesias infantis de João Köpke levam a elas uma diversidade de temas bem oportunos e, dentre eles, traz 
muitos aprendizados. Diante dessas afirmações, sabemos que o autor demonstra condições reais de ter sua obra estudada, já que, embora tenha escrito linhas qualificadas, não obteve o espaço devido na literatura infantil inserida nos âmbitos de pesquisa e difusão acadêmica.

\section{“MEU CAVALLO”: ESTÉTICA E AFETIVIDADE}

O poema escolhido para análise trata de uma brincadeira, uma cavalgada entre duas crianças (aparentemente): Lilitinha e Carolina. A primeira brinca de cavalinho nas costas da segunda, imaginando um cenário de campos, prados, bichos e cachoeiras, o que nos proporciona a criação da imagem da liberdade atribuída à infância. Percebemos a troca de afetividade que há entre ambas através de versos como os elencados abaixo.

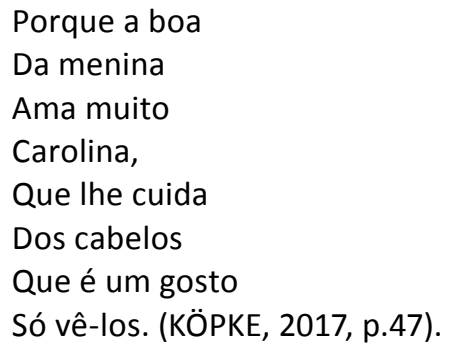

"Meu cavallo" é escrito em versos de quatro sílabas sonoras, disposto em vinte e duas quadras. Optando pelo trabalho com a poesia concreta, o autor dispõe as estrofes de modo desalinhado, dando a entender uma provável 
representação da cavalgada, isto é, o caminho que o cavalo percorre em seus galopes. São três fileiras: a primeira e a terceira em blocos que não ficam bem embaixo um do outro; a segunda, que é toda alinhada, evidencia o momento em que o cavalo está parado.

Jakobson (1978) chama a nossa atenção para a importância da função estética no âmbito da arte, afirmando que ela deve se sobressair, o que nos faz ponderar acerca da poesia infantil, que na maioria das vezes está vinculada ao didatismo, sem oferecer às crianças a possibilidade mais tangível do deleite. Para o autor, a poesia é quem nos protege contra a automatização que ameaça a difusão dos nossos sentimentos e só podemos falar nesse gênero quando há poeticidade na obra literária, um elemento que não pode ser reduzido ou desconsiderado.

Mas como se manifesta a poeticidade? A palavra é então experimentada como palavra e não como simples substituto do objeto nomeado, nem como explosão de emoção. As palavras e sua sintaxe, sua significação, sua forma externa e interna não são então indícios indiferentes da realidade, mas possuem o seu próprio peso e o seu próprio valor. (JAKOBSON, 1978, p.177)

O poema não deve ser apenas lido, mas sentido, imaginando seus contornos, imagens e provocações. A 
poeticidade aqui se encontra no ritmo, nas rimas, na expressividade, na forma, no conteúdo. A forma de "Meu cavallo" é capaz de provocar no leitor o prazer estético, embora não seja a única responsável por este feito. Além disso, há no decorrer da leitura figuras de linguagem como a gradação, que hierarquiza os termos que compõem uma frase, enfatizando um ritmo crescente que ruma ao clímax; a metáfora, que usa uma palavra ou uma expressão em um sentido que não é muito comum e a onomatopeia, que indica a reprodução de sons ou ruídos naturais. Lendo juntos, os versos são de sete sílabas poéticas.

Bosi (1988) conceitua a ideia de perspectiva afirmando que a mesma torna a leitura mais compreensível. A perspectiva deste poema, por exemplo, é infantil, lúdica, desprovida da pedagogia que imperava na época. A afetividade de Lilitinha por Carolina nos proporciona a sensação de leveza, podemos viajar no cavalinho através do deslocamento que se dá com o decorrer do texto. A alegria também está presente na fala da menina menorzinha ao ver o cuidado que Carolina Ihe tem, ajeitando seus cabelos para continuarem a jornada.

Annelados

A fugirem

Do lencinho

A cahirem.

Sobre a fonte

$E$ as orelhas 
Como, em bando

As abelhas.

Sobre a taça

D'uma flor

Carolina

Seu amor. (KÖPKE, 2017, p.47)

A questão da desautomatização está ligada à vida moderna. Desautomatizar também significa quebrar o mesmo modo de proceder em relação às diferentes esferas vitais. Mukarovský (1993), reflete acerca da denominação estética buscando as peculiaridades da denominação poética, embora ela não tenha um modelo pré-estabelecido. O contexto é significativo no discurso poético e a tendência estética produz esse contexto.

Assim, por exemplo, a frase $<<$ Chega o anoitecer $>$, que entendemos espontaneamente como uma informação, pode ser facilmente compreendida, mudando a intenção respeitante ao significado, como citação poética extraída de um texto imaginativo. [...] A denominação poética, portanto, não é determinada prioritariamente pela sua relação com a realidade que menciona, mas sim pela forma como se insere no contexto.

(MUKAROVSKÝ, 1993, p.178)

A denominação poética é diferenciada, por exemplo, da denominação comunicativa, que tem o objetivo de informar, apenas, não necessita exatamente de um contexto para 
ser compreendida. Seguindo esse entendimento, podemos considerar, no âmbito de um poema infantil, que lida diretamente com a fantasia, combinações lexicais que não necessariamente são aquilo que aparentam, que não existem na realidade.

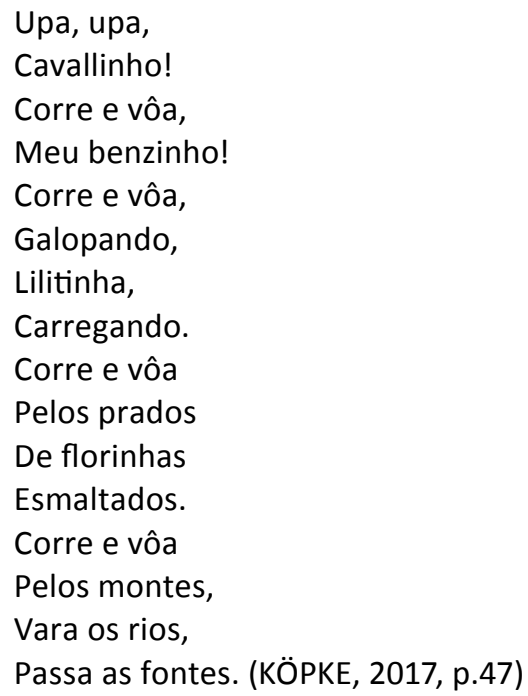

A menção ao voo do cavalinho, à possibilidade de ele pairar sobre prados, flores, montes, rios e fontes só pode ser concebida através da linguagem poética, por motivos que saltam aos olhos, pois trazendo para o contexto real, veríamos prontamente a impossibilidade de realização desses feitos. Além disso, no contexto do poema o cavalinho de Lilitinha é Carolina, fazendo menção a uma brincadeira que já perpassa várias gerações. 
Como a maioria dos poemas infantis, este percorre os caminhos do gênero lírico, evidenciando e valorizando o ritmo, a musicalidade, as imagens, dentre outros aspectos que no texto em questão tornam-se mais secundários. A lírica é a grande literatura para a sala de aula. Nela, sujeito e objeto se unem, os poemas devem ser lidos em voz alta e mais de uma vez visando senti-lo como é merecido, pois uma poesia pode até ter desvios gramaticais, mas havendo sentido e sonoridade chama a atenção dos leitores.

Para Steiger, "nem somente a música das palavras, nem somente sua significação perfazem o milagre da lírica, mas sim ambos unidos em um" (1975, p.23-24). O autor complementa afirmando que o poeta se detém, muitas vezes, à parte musical e desvia-se das regras de uso da linguagem, determinados pelo sentido, o tema e a rima. A lírica está ligada ao tempo presente, como é o caso de “Meu cavallo", que apresenta mais períodos coordenados do que subordinados e une o sujeito ao objeto.

A linguagem poética não é convencional e, portanto, não deveria ser confundida com a linguagem prática e informativa de outros gêneros. A poesia não intenciona servir como objeto engessado de investigação de atividades escolares, pois é continuamente desconstruída e reconstruída de acordo com 
a experiência estética de cada leitor. É necessário, assim, apresentá-la à criança sob o seu viés fantástico e deleitoso de realização.

\section{TRABALHANDO COM POESIA: UMA PROPOSTA METODOLÓGICA}

Considerando as distorções que existem no ambiente escolar em relação ao ensino de poesia na sala de aula, nos propomos a montar uma metodologia minimamente eficaz, do ponto de vista estético, à apreensão do alunado infantil quanto ao gênero lírico. Para isso, nos valeremos de teorias que contemplem a abordagem do poema na prática de ensino, bem como aquelas relativas ao método recepcional, isto objetivando um trabalho com poesia de modo mais fiel aos seus princípios. Vale ressaltar que utilizaremos como objeto o poema com o qual já viemos trabalhando no decorrer desse artigo.

Proposta metodológica

Conteúdo: poema

Texto literário: “Meu cavalo", de João Köpke

Público-alvo: primeira fase do ensino fundamental, alunos do $3^{\circ}$ ano

Objetivo: Proporcionar aos alunos uma aproximação mínima com a poesia, privilegiando as temáticas da musicalidade e dança

Procedimentos didáticos: etapas do método recepcional 
No primeiro momento, através de conversas informais, visaremos obter dos alunos informações relevantes do ponto de vista dos seus gostos, indagando-os acerca deles: se gostam de brincar, que tipo de brincadeira preferem, se já andaram a cavalo, como foi a experiência, se têm vontade de realizar um passeio assim, quais são os animais que preferem, se já leram poesia, em que ambiente e como isso se deu, se gostaram e o porquê, qual era o tema, dentre outras indagações que se fizerem pertinentes. Nessa ocasião de sondagem, buscaremos levar em consideração o universo particular dos alunos. Para Bordini e Aguiar, "[...] a atitude receptiva se inicia com uma aproximação entre texto e leitor, em que toda a historicidade de ambos vem à tona. As possibilidades de diálogo com a obra dependem do grau de identificação do leitor em relação a ela [...]" (1988, p.84).

No segundo momento, teremos um tempo estimado em 50 minutos, relativo a uma aula. Supondo que os alunos relataram o contato com a poesia, quer seja através do ouvir ou da leitura, organizaremos um círculo através do qual possamos iniciar o trabalho com o poema selecionado. Pediremos, então, para que os alunos também leiam o poema em voz alta, corroborando com Alves (2006), que afirma a importância que há na leitura oral do poema em 
sala de aula repetidas vezes. Cabe ao professor atribuir um verso ou estrofe a cada aluno, optando pela melhor maneira de conduzir o momento. A finalidade é promover um debate onde as crianças se sintam à vontade para manifestar suas impressões: que sentimentos lhes despertou? O que mais os impressionou na poesia? Como eles imaginavam a cavalgada das meninas? O que sentiram em relação à brincadeira e aos lugares pelos quais o cavalo passava?

Após esses direcionamentos, é relevante que se crie um espaço para os comentários e impressões dos alunos, assim como o professor, sobre o texto. Este deverá lançar questionamentos, enfatizando elementos que facilitem a compreensão e motivem a expressividade. Para a aula posterior, o professor poderá pedir que, em dupla, os alunos tragam poemas que tematizem brincadeiras infantis, de preferência com animais ou mesmo o cavalo.

No terceiro momento, em um tempo estimado em 50 minutos, o docente retomará a leitura do poema da aula anterior e relembrará as impressões obtidas. Posteriormente, o professor pedirá que os alunos se dividam nas duplas formadas para a pesquisa da aula anterior. Com tempo determinado, eles irão analisar seus poemas, retomando os questionamentos que foram feitos ao poema "Meu 
cavallo" e, a partir disso, o professor auxiliará cada grupo na mediação da conversa, didatizando, solicitando respostas as perguntas: os dois poemas têm o mesmo ritmo? Qual lhe agrada mais? Que brincadeira faz parte do seu cotidiano? De qual você mais gosta? Ao final das respostas, cada dupla irá ler em voz alta para os demais, permitindo a interação entre eles. Uma sugestão possível para todos os grupos é a de dramatizar a cavalgada refletida no poema analisado, nesse momento pode-se pedir aos demais que façam o som enquanto a dupla dramatiza o ritmo.

No quarto e último momento o professor deverá mostrar um simples e pequeno painel, pedindo que as crianças o ajudem na confecção de um bonito quadro, com desenhos relacionados aos poemas, para que cada dupla coloque lá o poema escolhido, possibilitando que ele fique visível em sala de aula, mostrando aos alunos a relevância que há nas suas escolhas textuais, de modo que aqueles poemas estejam ao alcance da mão e da vista deles sempre que quiserem novamente ter algum contato com a poesia. É proveitoso ressaltar que construir um cantinho para fixar vários tipos de poesia é um método eficaz para o incentivo da leitura e interpretação poética, pois quanto mais se lê, mais se aprende e cria o hábito da leitura não só de poesia como de outros tipos de textos. 


\section{CONSIDERAÇÕES FINAIS}

Optamos por nos deter ao poema "Meu cavallo", contido em Versos para os pequeninos, por ter sua qualidade literária constatada, bem como por ter sido escrito há mais de um século, tendo sido editado só agora. Percebemos na referida obra uma linha temática que se complementa à medida que se lê. Não só essa, mas outras obras são unidas em um projeto literário do autor, evidenciando a sua ligação ao cotidiano infantil. Vemos em seus textos um anseio contemporâneo em lidar com assuntos pertinentes às crianças, o que se dá através de uma perspectiva estética satisfatória.

Este artigo constitui um breve estudo acerca de João Köpke, a exemplificação e análise de um poema da sua obra e as questões com as quais o professor deve se atentar para o trabalho com o gênero lírico em sala de aula, através de uma simples proposta metodológica. A poesia infantil, assim como muitos outros gêneros, tem suas especificidades, considerando sua estrutura, organização, compreensão, o que faz com que tenhamos de conhecê-la para, só depois, poder levá-la ao ambiente escolar. A análise criteriosa dos textos, buscando aqueles que melhor falem ao mundo infantil, é fundamental.

Um ponto que não pode ser negligenciado é que o professor precisa levar a criança a conviver com a poesia, mas, para isso, precisa ele mesmo conhecer a produção, 
passar pela experiência de ler, sentir, discutir, refletir sobre ela, até mesmo produzir, uma vez que só assim estará preparado para mediar essa experiência tão relevante para criança. Nossa proposta não pode ser vista como como produto acabado, pois, como o próprio nome diz, apenas propõe uma forma de se trabalhar com a poesia, estando, portanto, aberta a modificações e melhoramentos.

Os temas que podem permear o texto literário são muitos e na poesia como um todo não há limites para representar esse vasto temário. O que acontece é que, quando se trata da poesia infantil, muitas vezes nos deparamos com restrições que se dão devido a esse tipo de destinatário, sejam em razão de imposições sociais, do período de maturação que a criança se encontra ou pelas exigências escolares. Para amenizar o distanciamento da interpretação e da compreensão poética, o professor precisa ter o manejo necessário para não desencadear restrições por parte do alunado, este que não tem sequer o livro didático como aliado, nesse sentido, o que só corrobora com a necessidade premente de um trabalho mais adequado com o gênero lírico.

\section{REFERÊNCIAS}

ALVES, José Helder Pinheiro (2010). "Poesia para crianças: novos livros, novos autores". In: RÖSING, T. M. K.; BURLAMAQUE, F. V (Org.). De casa e de fora, de antes e de agora: estudos de literatura infantil e juvenil. Passo Fundo: Editora Universidade de Passo Fundo, p.241-266. 
(2016). "Estratégias para o ensino de poesia". In: FERNANDES, Maria Lucia Outeiro; ANDRADE, Paulo; PERRONE, Charles A (Org.). Poesia na era da internacionalização dos saberes: circulação, tradução, ensino e crítica no contexto contemporâneo. São Paulo: Cultura Acadêmica, p.207228.

BOSI, Alfredo (1988). "A interpretação da obra literária". In: . Céu, inferno: ensaios de crítica literária e ideologia. São Paulo: Ática. p.274-287. CADEMARTORI, Ligia (2009). O professor e a literatura: para pequenos, médios e grandes. Belo Horizonte: Autêntica.

CAMARGO, L (2001). "A poesia infantil no Brasil". Revista de Crítica Literaria Latinoamericana. Ano 27, (53), 87-94. In http://www.jstor.org/ stable/4531150 Acesso em 20.Set.2017.

FERREIRA, Norma Sandra de Almeida (2016a). "Uma apresentação do manuscrito inédito de João Köpke: Versos para os pequeninos". Leitura: Teoria \& Prática. Campinas, São Paulo. 34(67), 51-67.

JAKOBSON, Roman (1978). “O que é a poesia?" In: TOLEDO, Dionísio. Círculo linguístico de Praga: estruturalismo e semiologia. Zênia de Faria, Reasylvia de Toledo e Dionísio Toledo (Trad.). Introdução de Julia Kristeva. Porto Alegre: Globo, p.167-193.

KÖPKE, João (2017). Versos para os pequeninos. FERREIRA, Norma Sandra de Almeida (Org.). Edição fac-similiar, Fapesp: In http://revistapesquisa. fapesp.br/wp-content/uploads/2017/03/kopke-facsimile.pdf Acesso em 15.Set.2017.

(2017). João Köpke, precursor de Monteiro Lobato: obra de escritor e educador é objeto de tese de livre docência. Entrevista concedida ao Jornal da Unicamp. In https://www.unicamp.br/unicamp/ju/ noticias/2017/05/23/joao-kopke-precursor-de-monteiro-lobato Acesso em 30.Set.2016.

MUKAROVSKY, Jan (1988). Escritos sobre estética e semiótica da arte. Manuel Ruas (Trad.). Lisboa: Editorial Estampa, p.177-193.

OLIVEIRA, Valnikson Viana (2017). As raízes da poesia infantil de Zalina Rolim em livro das crianças. 143p. (Dissertação - Mestrado em Letras). Universidade Federal da Paraíba. 
STEIGER, Emil (1975). Conceitos fundamentais da poética. Celeste A. Galeão (Trad.). Rio de Janeiro: Tempo Brasileiro, p.19-75.

Morgana de Medeiros Farias é Mestra (2017) em Letras pela UFPB - CNPq, atualmente é aluna de doutorado desta mesma instituição e trabalha com temas voltados ao universo da literatura infantil, como gênero, cultura e sociedade. Participou do livro Nos sábados à tarde (2012), editado pela EDUEPB e publica artigos na mesma área citada, tendo sido o último na Revista Palimpsesto, denominado "Entre leão e unicórnio": o conto colasantiano pelos caminhos do efeito estético (2019). Atualmente participa do grupo de pesquisa "Estágio, ensino e formação docente" (http://www.ufpb.br/geef), na Universidade Federal da Paraíba.

E-mail: morgananp14@hotmail.com.

ORCID iD: https://orcid.org/0000-0002-6808-6715

Maria Daniela Segabinazi é Doutora em Letras pela Universidade Federal da Paraíba (2011), vinculado a área de Literatura, Cultura e tradução, linha de Estudos literários da Idade Média ao Século XIX. Atualmente integra o quadro de professores da Universidade Federal da Paraíba (UFPB), com dedicação exclusiva e é líder do grupo de pesquisa "Estágio, ensino e formação docente" (http://www.ufpb.br/geef). É autora e orientadora de diversos artigos, bem como é engajada em vários projetos de pesquisa voltados área de Letras e Pedagogia, com ênfase em Literatura infantojuvenil, literatura brasileira, ensino de literatura, estágio supervisionado e formação de professores; atuando principalmente nos seguintes temas: práticas pedagógicas, literatura e ensino, literatura infantil e juvenil, leitura e letramento literário. Sou produção mais recente denomina-se "Ensinar e aprender literatura na escola: o que dizem os professores e alunos", (2019).

E-mail: dani.segabinazi@gmail.com

ORCID iD: https://orcid.org/0000-0002-5344-775X 